\title{
A Study on the Evaluation of Agricultural Modernization in China
}

\author{
Yanhua CHANG ${ }^{1}$ and Bo SHI ${ }^{2}$ \\ 1 Shanxi Institute of Business and Technology, Xiaodian District, Taiyuan City, Shanxi Province; \\ 393629332@qq.com \\ 2 School of Economics and Management, Northwest University, Chang'an District, Shaanxi Province; \\ shibonwu@sina.com \\ * Corresponding author: 393629332@qq.com
}

\begin{abstract}
In this paper an agricultural modernization evaluation system is constructed from four dimensions, and by using entropy method the comprehensive index of agricultural modernization is calculated in 31 provinces (including central government directly administrated municipalities, autonomous regions) in China. The results show that the level of agricultural modernization in China is generally on the rise and is in the initial stage of modernization. In terms of various regions, the level of agricultural modernization is in the following order: the eastern region, the northeast region, the central region, and the western region. There is an obvious gap between different regions in agricultural modernization, with Beijing, Shanghai and other places in the leading position, and Qinghai, Gansu and other places at the bottom. Accordingly, policies should be put forward, including increasing the input of agricultural modernization and carrying out development strategies for different regions.
\end{abstract}

Keywords: agricultural modernization; index system; entropy value method; evaluation

JEL Classification: F32; F72

\section{Introduction}

In a session of the National People's Congress in 1954, the then Premier Zhou Enlai, put forward the concept of the "four modernizations", including agricultural modernization, reform and opening up to now, since then, a number of central documents and conferences have emphasized and proposed the theme of promoting agricultural modernization, which fully demonstrates the importance attached by the party and the state to the issue of agriculture, rural areas and farmers. Although China's agricultural modernization has made considerable progress, its agricultural foundation is still weak on the whole, which is an obvious weak part in the "Four Modernizations" (Zhang, 2015). In October 2016, the State Council issued the National Plan for Agricultural Modernization (2016-2020), which points out the direction for the objective evaluation of agricultural modernization.

As for the evaluation of agricultural modernization, scholars have used many methods to conduct research, mainly including Delphi method, analytic hierarchy process, principal component analysis method, key parameter comparison method and other measurement methods. For example, Delphi method and multi-level analysis method are combined to carry 
out comprehensive measurement from four aspects including agricultural input, agricultural output, rural social development and agricultural sustainable development (Zhong, 2018). The agricultural modernization evaluation system is divided into four dimensions (output, population, benefit, technology) and 15 basic indicators by using principal component analysis, and the main influencing indicators of agricultural modernization are extracted to measure the agricultural modernization index (Zhang, 2016). Select representative indicators of agricultural modernization to comprehensively compare the gap between Jiangsu Province and developed countries (Liy, 2012). This document provides a reference for the evaluation of agricultural modernization research, especially provide a mature index system, try to build from four dimensions, using entropy method to measure agricultural modernization of China's 31 provinces composite index, to grasp the different province agricultural modernization level and the regional difference, in order to promote agricultural modernization development theory and data support.

\section{Construction of Agricultural Modernization Evaluation Index System}

\subsection{Construction of Index System}

This paper follows the basic principles of systematization, emphasis and operability, combines the concept and actual situation of agricultural modernization in China, and refers to the representative evaluation index system of agricultural modernization in China (Long et al., 2014; Chen et al., 2018; Du et al., 2018). From four dimensions of agricultural input, agricultural comprehensive output, rural social development and agricultural ecology, the evaluation index system of China's agricultural modernization was constructed. Agricultural input level includes indicators such as machinery, science and technology, land and capital; the comprehensive agricultural output level includes the land output rate, agricultural labor productivity, grain output per unit cultivated land area, added value of agriculture, forestry, animal husbandry and fishery, etc. The level of rural social development includes the urbanization rate, urban residents' income level, Engel's coefficient and other index factors. The level of agricultural o-ecological level includes the rate of water-saving irrigation, the coverage rate of greening, the rate of agricultural disaster, the amount of fertilizer applied, the area of soil erosion control, the coverage rate of forest and other index factors (see Table 1).

\subsection{Research Methods}

In this study, entropy method was used. Firstly, the indexes were standardized. Secondly, MATLAB software was used to calculate the entropy value and weight of each index. Finally, according to the weights determined, the comprehensive evaluation value of agricultural modernization development level of 31 Provinces (including central government directly administrated municipalities, autonomous regions) in China from 2009 to 2018 was calculated. 


\section{A STUDY ON THE EVALUATION OF AGRICULTURAL MODERNIZATION IN CHINA}

Table 1. Evaluation index system of China's agricultural modernization

\begin{tabular}{|c|c|c|c|c|}
\hline $\begin{array}{c}\text { Level } \\
\text { indicators }\end{array}$ & The secondary indicators & Index calculation & Unit & Weight \\
\hline \multirow{4}{*}{$\begin{array}{l}\text { Agricultural } \\
\text { input level }\end{array}$} & Total power of farm machinery & Total power of agricultural machinery/total arable area & $\mathrm{kw} / \mathrm{hm} 2$ & $5 \%$ \\
\hline & $\begin{array}{l}\text { Labor all agricultural science and technology } \\
\text { input }\end{array}$ & $\begin{array}{c}\text { Total number of agricultural science and technology } \\
\text { personnel/total population of primary industry }\end{array}$ & $\%$ & $6 \%$ \\
\hline & Effective irrigation rate & Irrigation area of cultivated land/area of cultivated land & $\%$ & $5 \%$ \\
\hline & Financial support for agriculture and rural areas & Total amount of financial support for agriculture/arable land & $\%$ & $14 \%$ \\
\hline \multirow{4}{*}{$\begin{array}{l}\text { Agricultural } \\
\text { synthetical } \\
\text { output level }\end{array}$} & Land yield rate & Gross agricultural output value/cultivated area & Yuan $/ \mathrm{hm}^{2}$ & $8 \%$ \\
\hline & Agricultural labor productivity & Gross agricultural output value/total rural population & 10,000Yuan/person & $4 \%$ \\
\hline & Grain output per unit cultivated area & Total grain output/total arable area & $\mathrm{kg} / \mathrm{hm}^{2}$ & $5 \%$ \\
\hline & $\begin{array}{l}\text { Added value of agriculture, forestry, animal } \\
\text { husbandry and fishery }\end{array}$ & $\begin{array}{l}\text { Added value of agriculture, forestry, animal husbandry and } \\
\text { fishery/gross output value of agriculture, forestry, animal } \\
\text { husbandry and fishery }\end{array}$ & $\%$ & $2 \%$ \\
\hline \multirow{3}{*}{$\begin{array}{l}\text { Rural social } \\
\text { development } \\
\text { level }\end{array}$} & Rate of urbanization & Urban population/total population & $\%$ & $4 \%$ \\
\hline & Income level of urban and rural residents & Per capita disposable income of urban and rural residents & $\%$ & $3 \%$ \\
\hline & Engel coefficient & $\begin{array}{l}\text { Food expenditure/total consumption expenditure of rural } \\
\text { residents }\end{array}$ & $\%$ & $4 \%$ \\
\hline \multirow{4}{*}{$\begin{array}{l}\text { Agricultural } \\
\text { ecological } \\
\text { level }\end{array}$} & Agricultural disaster rate & Total disaster area/total disaster area & $\%$ & $6 \%$ \\
\hline & $\begin{array}{c}\text { Application amount of agricultural chemical } \\
\text { fertilizer }\end{array}$ & Fertilizer application rate/arable land area & $\mathrm{kg} / \mathrm{hm} 2$ & $4 \%$ \\
\hline & Control area of soil erosion & Soil erosion control area & hm\&sup2 & $25 \%$ \\
\hline & Percentage of forest cover & Total forest area/total land area & $\%$ & $5 \%$ \\
\hline
\end{tabular}


Standardization of index values

In order to eliminate the influence of dimension between each index, the entropy method is used to standardize the index. The calculation formula is as follows:

Positive indicators:

$$
Y_{i j}=\left(X_{i j}-X_{\min }\right) /\left(X_{\max }-X_{\min }\right)
$$

Negative indicators:

$$
Y_{i j}=\left(X_{\max }-X_{i j}\right) /\left(X_{\max }-X_{\min }\right)
$$

In Equations (1) and (2), $Y_{i j}$ is the standardized value of the ITH index of the ith sample, $X_{i j}$ is the original value of the $I T H$ index of the ${ }^{i t h}, X_{\max }$ and $X_{\min }$ are the maximum and minimum values of the ITH index respectively.

\section{Determination of weights}

Calculate the proportion of each index according to formula

$$
C_{i j}=Y_{i j} / \Sigma_{i=1}^{n} Y_{i j}
$$

According to Equation (4), the entropy of index $j$ can be calculated:

$$
e_{j}=-\frac{1}{\operatorname{lnn}} \sum_{i=1}^{n} C_{i j} \ln C_{i j}
$$

Difference coefficient of the $j$ index was calculated according to Equation

$$
d_{j}=1-e_{j}
$$

Calculate the weight of each index according to Equation

$$
w_{j_{=}} d_{j} / \sum_{j=1}^{m} d_{j}
$$

The comprehensive evaluation value is calculated according to Equation

$$
V_{i}=\sum_{j=1}^{m} w_{j} Y_{i j}
$$

\subsection{Data Sources}

The research uses the related data from the China Statistical Yearbook of Land and Resources, Science and Technology of China Statistical Yearbook, "China Water Resources Statistical Yearbook, China Statistical Yearbook, China rural statistical yearbook, China Environment Statistical Yearbook, the Population of China Statistical Yearbook, China Forestry Database and the Provincial publicly available data. 


\subsection{Stage Division}

Based on the evaluation of agricultural modernization at home and abroad, according to the characteristics of agricultural development, this study divides agricultural modernization into preparation stage, starting stage, preliminary realization stage, basic realization stage and comprehensive realization stage. The comprehensive evaluation value range are respectively, [0-0.3], [0.3-0.5], [0.5-0.7], [0.7- 0.9], [0.9-1].

\section{Comprehensive Evaluation of the Level of Agricultural Modernization in China}

\subsection{The Level of Agricultural Modernization Is on the Rise}

In this paper, the entropy method was used to standardize 15 original data of 31 Provinces (including central government directly administrated municipalities, autonomous regions) in China from 2009 to 2018, and the corresponding evaluation value was calculated to analyze the development trend of China's agricultural modernization level and regional differences (see Figure 1 and Figure 2).As shown in Figure 1, the level of agricultural modernization in China is on the rise as a whole, from 0.25 in 2009 to 0.53 in 2018, with an average annual growth rate of $9.6 \%$. Although there have been some fluctuations in individual years, the overall upward fundamentals have not been affected.

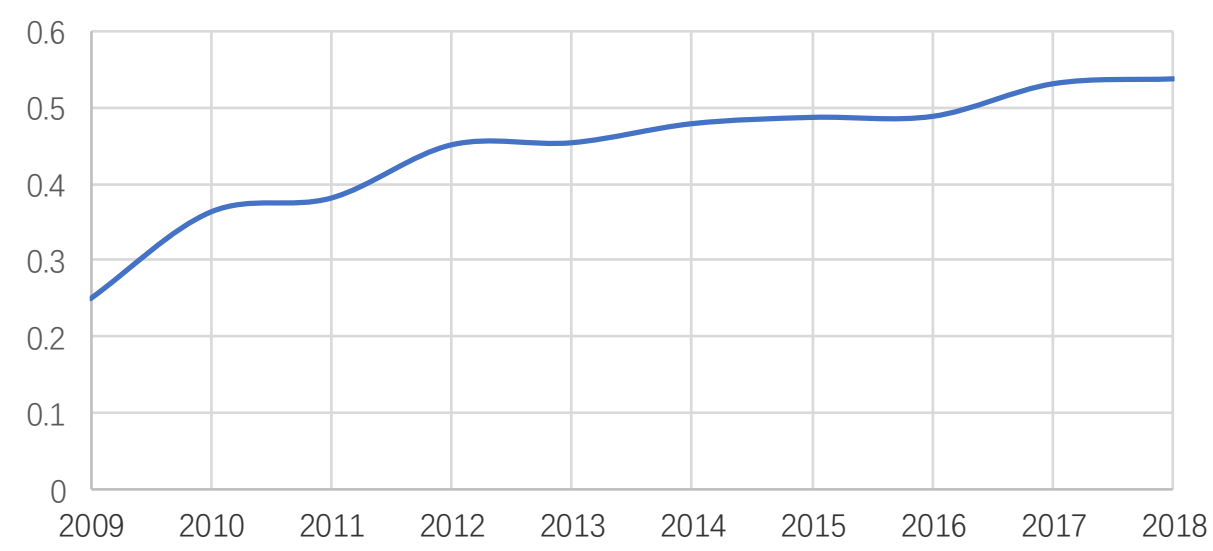

Figure 1. Development level of China's agricultural modernization from 2009 to 2018

\subsection{The Development Level of Agricultural Modernization in Various Regions is Obviously Different}

In this paper, Provinces in China are categorized into eastern, central, western and northeast regions, and the change status of the comprehensive evaluation index of China's agricultural modernization in 2018 is obtained by evaluation, as shown in Figure 2.The comprehensive index of agricultural modernization in the eastern region is 0.59 , which is the region with the fastest development of agricultural modernization, followed by the northeast region with 0.54 .The comprehensive index of agricultural modernization in central China is 0.53 .The comprehensive index of agricultural modernization in the western region is 0.52 , which is the slow development among the four regions. The reason is that the comprehensive index of some Provinces in the western region, such as Qinghai, Guizhou, 
Inner Mongolia and Chongqing, is relatively low and in the initial stage of agricultural modernization development, which affects the development of agricultural modernization in the western region to a large extent.

There is significant agricultural modernization level gap, Beijing, Shanghai and some other Provinces have been in the forefront; Qinghai, Gansu, and some others are in the bottom. For example, in 2013 the absolute gap between Beijing and Qinghai was 0.262, and it increased to 0.271 in 2015, 0.394 in 2018, showing a trend of widening the absolute gap.

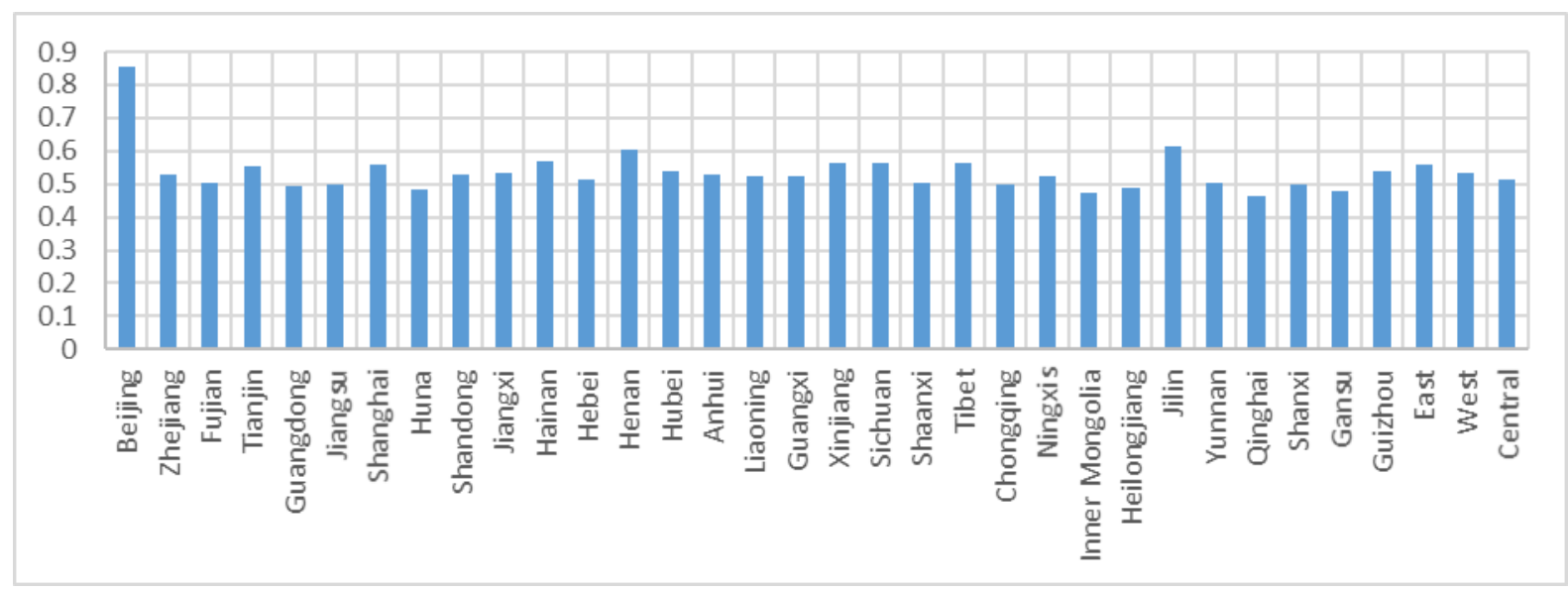

Figure 2. Comprehensive index of Agricultural modernization development in China in 2018

\section{Conclusions and Policy Suggestions}

\subsection{Conclusion}

The results show that the development level of agricultural modernization in China is generally on the rise from 2009 to 2018, and it is in the preliminary realization stage of modernization. At the same time, the level of agricultural modernization in different regions is quite different, the gradient is rising and the whole level is low. First of all, there is a large gap in the level of agricultural modernization in different regions. The level of agricultural modernization in Beijing, Shanghai and other places is in the leading position in the country, and the level of agricultural modernization in Qinghai, Gansu and other places is in the last place, with great differences, which is reflected in the differences of various indicators. Secondly, from the perspective of sub-regions, the development level of agricultural modernization shows an upward trend of gradient in western region, central region, northeast region and eastern region. Thirdly, the areas that have initially realized agricultural modernization and those that have basically realized agricultural modernization, although the growth rate is fast, the comprehensive index of agricultural modernization is low, the shortcoming is prominent, and the agricultural modernization is at the overall low level.

\subsection{Based on the Analysis, the Following Suggestions are Put forward for China's Agricultural Modernization}

To increase input in agricultural modernization. First, government funding should be increased and be focused on solving problems such as weak agricultural infrastructure. 
Second, input should be increased in agricultural science and technology, encourage the establishment of agricultural research projects, organize agricultural research institutes, colleges and universities and enterprises to jointly tackle technological problems, and accelerate the transformation of scientific and technological achievements. Third, the comprehensive quality of professional farmers should improve. To train a group of skillful and professional farmers, understanding and technology, good management is important.

In order to improve the overall level of agricultural modernization, different strategies should be adopted in combination with the actual situation of each region. For the regions that are located between the initial stage and the basic stage of realization, they should base on the geographical advantages, optimize the allocation of agricultural resources, improve the utilization rate of resources, pay attention to the improvement of resources and environment, maintain the leading position in the country, and take the lead in entering the basic realization stage. For the regions which are located at the initial stage and ready for development. The policy should focus on, in light of their actual conditions, finding gaps and strengthen weak links so as to further increase their overall agricultural production capacity and speeding up economic development.

\section{References}

Zhang, H. Y. et al. (2015). Agricultural modernization with Chinese characteristics: objective positioning, reform and innovation. Chinese Rural Economy, 1, 4-13.

Zhong, L. N., \& Li, S. B. (2018). Evaluation on the Development Level of Agricultural Modernization in Shaanxi Province. Research on Agricultural Modernization, 1, 57-64.

Zhang, H., \& Li, B. (2016). Comprehensive evaluation of agricultural modernization level in China. Rural Economy, 12, 53-57.

$\mathrm{Li}, \mathrm{X}$. et al. (2012). The difference of agricultural modernization level between Jiangsu and developed countries. Jiangsu Agricultural Sciences, 12, 385-387.

Long, D. P., Li, T. S., Miao Y.Y., \& Yu, Z. S. (2014). Spatial differentiation and types of agricultural modernization development in China. Acta Geographica Sinica, 2, 214-226.

Chen J. T., Zhang, Q. H., \& Lv, J. Q. (2018). Evaluation of the level of agricultural modernization in China and its influencing factors. Chinese Journal of Agricultural Resources and Regional Planning, 2, 205-213.

Du, Y. E., Pan, C. Y., \& Song, S. F. (2018). Evaluation of the degree of agricultural modernization in China based on the agricultural statistical data of different provinces. Agrotechnical Economics: 3, 79-89. 